\title{
Mycoremediation of Old and Intermediate Landfill Leachates with an Ascomycete Fungal Isolate, Lambertella sp.
}

\author{
Giovanna Siracusa ${ }^{1}$, Qiuyan Yuan ${ }^{2}{ }^{\oplus}$, Ilaria Chicca ${ }^{1,2,3}$, Alessandra Bardi ${ }^{4}$, \\ Francesco Spennati ${ }^{5}$ (D), Simone Becarelli ${ }^{1,6}$, David Bernard Levin ${ }^{3}$, Giulio Munz ${ }^{4}$, \\ Giulio Petroni ${ }^{1}$ and Simona Di Gregorio ${ }^{1, *}$ \\ 1 Department of Biology, University of Pisa, 56123 Pisa, Italy; giovanna.siracusa@biologia.unipi.it (G.S.); \\ ilaria.chicca@biologia.unipi.it (I.C.); simone.becarelli@biologia.unipi.it (S.B.); giulio.petroni@unipi.it (G.P.) \\ 2 Department of Civil Engineering, University of Manitoba, 15 Gillson Street, Winnipeg, MB R3T 5V6, Canada; \\ Qiuyan.Yuan@umanitoba.ca \\ 3 Department of Biosystems Engineering, University of Manitoba, 75 Chancellor Circle, Winnipeg, \\ MB R3T 5V6, Canada; David.Levin@umanitoba.ca \\ 4 Department of Civil and Environmental Engineering, University of Florence, Via S. Marta 3, 50139 Florence, \\ Italy; alessandrabardi85@gmail.com (A.B.); giulio.munz@unifi.it (G.M.) \\ 5 Cer2Co Lab, Consorzio Cuoio Depur S.p.a., Via Arginale Ovest 81, San Miniato, 56020 Pisa, Italy; \\ francesco.spennati@cuoiodepur.it \\ 6 BD Biodigressioni srl, Lung'Arno Mediceo 40, 56127 Pisa, Italy \\ * Correspondence: simona.digregorio@unipi.it
}

Received: 12 February 2020; Accepted: 10 March 2020; Published: 13 March 2020

\begin{abstract}
In the present study, an Ascomycete fungal strain, Lambertella sp., isolated from environmental polluted matrices, was tested for the capacity to reduce the contamination and the toxicity of intermediate and old landfill leachates. Batch tests in flasks, under co-metabolic conditions, were performed with two different old leachates, with suspended and immobilized Lambertella sp. biomass, resulting in a soluble chemical oxygen demand depletion of $70 \%$ and $45 \%$, after 13 and 30 days, respectively. An intermediate landfill leachate was treated in lab-scale reactors operating in continuous conditions for three months, inoculated with immobilized Lambertella sp. biomass, in absence of co-substrates. The Lambertella sp. depleted the corresponding total organic carbon by $90.2 \%$. The exploitability of the Lambertella sp. strain was evaluated also in terms of reduction of phyto-, cyto-, and mutagenicity of the different Landfill Leachates at the end of the myco-based treatment, resulting in an efficient depletion of leachate clastogenicity.
\end{abstract}

Keywords: ascomycetes; bioaugmentation; Lambertella sp.; landfill leachate; organic compound removal; reactor scale; toxicity depletion

\section{Introduction}

Landfill Leachates (LFLs) are the aqueous effluents produced by landfills as a result of the leaching of the moisture and rainwaters from the contained wastes. The leaching process creates polluted aqueous matrices composed by different classes of organic and inorganic compounds, recalcitrant to biodegradation and toxic for the environment. These contaminants are often found at high concentrations and some of them are recalcitrant to biodegradation, comprising humic and fulvic acids and polycyclic aromatic hydrocarbons, and metals that autochthonous microorganisms in landfills are unable to transform or degrade [1-6]. With the aging of LFLs, the ratio between the Biological Oxygen Demand measured at day $5\left(\mathrm{BOD}_{5}\right)$ and the Chemical Oxygen Demand $\left(\mathrm{BOD}_{5} / \mathrm{COD}\right)$, decreases 
because of the hydrolysis/oxidation of the biodegradable organic fraction of leachates, while the non-biodegradable fraction of the COD remains unchanged. The value of the $\mathrm{BOD}_{5} / \mathrm{COD}$ ratio is the reference for the definition of the LFL's recalcitrance to biodegradation-young LFL, intermediate LFL, and old LFL, with old LFLs being the most recalcitrant to biodegradation, due to the near absence of a biodegradable $\mathrm{BOD}_{5}$ and a very recalcitrant residual COD [7].

While conventional biological treatments, such as activated sludge, aerated lagoons, sequencing batch reactors, up-flow anaerobic sludge blanket, membrane bioreactors, are widely and often used successfully to treat young leachates [8,9], biological treatments are hampered by the toxicity and recalcitrance of intermediate and old leachates [10]. That is why strategies adopted to reduce the organic and inorganic loads in LFLs are generally chemical-physical processes, which might be expensive and not always effective in removing all the toxic and recalcitrant compounds. Physical-chemical treatments such as classic Fenton or combined Fenton processes, evaporation, and/or Advanced Oxidation Processes (AOPs) applied on LFLs are energy-intensive processes and often generate matrices with a residual level of toxicity [11], causing the accumulation of secondary metabolites, often more toxic than the initial pollutants [11-13], that impede the safe discharge of the treated LFLs.

On the other hand, the actual bio-based processes for wastewater treatments, exploiting mainly bacteria in oxidative or anaerobic processes, are effective in the LFLs nitrification/denitrification, but not necessarily effective for the depletion of organic and inorganic toxic compounds [3]. Moreover, the treatment of intermediate and/or old leachates still remains a challenge, hampering the good functioning of all the systems, calling for dedicated intervention [14,15].

Promising results for the treatment of the latter have been described with a combination of physical-chemical and bio-based treatments $[3,8,16,17]$. Recent reports in the literature have focused on combinations of different technologies to improve wastewater treatments by removing residual contamination and toxicity with innovative, bio-based, and cost-sustainable treatments that utilize plants, microalgae, and yeasts [16,18-23].

During the last decade, innovative fungal-based processes (myco-remediation) have also been studied and results, in terms of depletion of recalcitrant compounds in wastewater streams, have been described [24-28]. Fungi may be exploited for their oxidative capacities towards compounds recalcitrant to bacterial degradation [28,29]. In particular, many Basidiomycete fungi have been applied in the reduction of the COD of synthetic and real LFLs, because they secrete a battery of extracellular, lignin-degrading enzymes with low substrate specificity [2,24,25,30], which enable fungi to transform recalcitrant phenolic and/or aromatic compounds in different environmental matrices [31-33].

Although myco-remediation studies on LFLs have focused primarily on the exploitation of Basidiomycetes [5,34], Ascomycota are described as dominant in wastewater treatment streams [30,35], and their metabolic capacities might have been underestimated in the design of myco-based approaches to the decontamination of LFLs.

In the present work, the capability of the Ascomycete Lambertella sp., previously characterized for its capacity to deplete petroleum hydrocarbons from environmental matrices [36], to remove organic pollutants and toxic compounds from intermediate and old LFLs was investigated in flaskand reactor-scale experiments. Batch tests under co-metabolic conditions in flasks were performed on different old leachates, with suspended and immobilized fungal biomass. Lab-scale reactors operating under continuous conditions, inoculated with the immobilized fungal biomass, in absence of co-substrates, were used to treat an intermediate leachate. The depletion of the recalcitrant to biodegradation loads of the different leachates was measured in parallel to Mn-dependent and independent peroxidase activities, laccase activity and the phytotoxic, cytotoxic, and genotoxic effects of the different LFLs, before and after the myco-based treatment. 


\section{Materials and Methods}

\subsection{Inoculum and Immobilization of Fungal Strain}

The Lambertella sp. strain used in all experiments was isolated and described by [36]. The Lambertella sp. was inoculated as immobilized biomass on Polyurethane Foam cubes (PUFs) of $4 \mathrm{~cm}^{2}$ side (specific surface $600 \mathrm{~m}^{2} \mathrm{~m}^{-3}$, density $25 \mathrm{~kg} \mathrm{~m}^{-3}$, Pores/Volume ratio: 0.97) as follow. The Lambertella sp. strain, routinely cultivated on Malt Extract Agarized broth (MEA, Malt $20 \mathrm{~g} / \mathrm{L}$, Yeast extract $5 \mathrm{~g} / \mathrm{L}, 15 \mathrm{~g} / \mathrm{L}$ agar in water) agarized plates, was grown in Malt Extract Broth (MEB, Malt $20 \mathrm{~g} / \mathrm{L}$, Yeast extract $5 \mathrm{~g} / \mathrm{L}$ in water), homogenized under sterile conditions, and incubated with sterile PUF cubes, at $24^{\circ} \mathrm{C}$, for 7 days at $150 \mathrm{rpm}$, in the dark, in order to immobilize the fungal biomass on the solid supports. The fungal biomass immobilized on PUFs was filtered, under sterile conditions, and washed with sterile saline water $(\mathrm{NalCl} 0.9 \mathrm{~g} / \mathrm{L}$ in water) and transferred into flasks and bioreactors for batch and continuous tests, respectively.

\subsection{Leachate Characterization}

Old raw leachate was sampled in 50 L polypropylene tanks at the Municipal Summit Road landfill, Winnipeg, Canada $\left(49^{\circ} 55^{\prime} 14.938^{\prime \prime} \mathrm{N} ; 97^{\circ} 18^{\prime} 38.379^{\prime \prime} \mathrm{E}\right)$ at the outlet of the leachate collector pump and transported in a walking-in refrigerated chamber $\left(4^{\circ} \mathrm{C}\right)$ at the Biosystems engineering Department of the local University and processed the successive day. A second old LFL and an intermediate LFL from Cuoio Depur s.p.a. tannery Wastewater Treatment Plant (WWTP), San Romano, Italy $\left(43^{\circ} 41^{\prime} 44.6^{\prime \prime} \mathrm{N}\right.$; $\left.10^{\circ} 46^{\prime} 2.7^{\prime \prime} \mathrm{E}\right)$, were sampled in $50 \mathrm{~L}$ polypropylene tanks, at the outlet of the leachate collector pump of the transporting trackers entering in the WWTP. The tanks were stored in the local walking-in refrigerated chamber $\left(4^{\circ} \mathrm{C}\right)$ and processed the successive day. The characterization of the LFLs was conducted according to the standard methods [37] and reported in Table 1. The leachates are classified as old when the COD is lower than $4000 \mathrm{mg} \mathrm{L}^{-1}$ and the $\mathrm{BOD}_{5} / \mathrm{COD}$ ratio is lower than 0.1 ; intermediate leachate in the case the $\mathrm{BOD}_{5} / \mathrm{COD}$ ratio is lower than 0.5 but higher than 0.1 . Leachate characteristics are listed in Table 1.

Table 1. Characteristics of the old, and intermediate Landfill Leachates (LFLs).

\begin{tabular}{|c|c|c|}
\hline Leachate Name & Component & Concentration \\
\hline \multirow{4}{*}{ Summit Road old leachate } & Total Nitrogen & $104.0 \pm 2.1$ \\
\hline & COD & $1507.0 \pm 242.5$ \\
\hline & $\mathrm{BOD}_{5}$ & $\leq 0.27$ \\
\hline & $\mathrm{pH}$ & $7.8 \pm 0.2$ \\
\hline \multirow{4}{*}{$\begin{array}{c}\text { Cuoio Depur WWTP old } \\
\text { leachate }\end{array}$} & Total Nitrogen & $460.0 \pm 1.3$ \\
\hline & COD & $1800.0 \pm 101.3$ \\
\hline & $\mathrm{BOD}_{5}$ & $78 \pm 1.5$ \\
\hline & $\mathrm{pH}$ & $7.52 \pm 0.4$ \\
\hline \multirow{5}{*}{$\begin{array}{l}\text { Cuoio Depur WWTP } \\
\text { intermediate leachate }\end{array}$} & Total Nitrogen & $490.0 \pm 2.7$ \\
\hline & COD & $526.0 \pm 23.8$ \\
\hline & $\mathrm{BOD}_{5}$ & $90.0 \pm 1.2$ \\
\hline & $\mathrm{pH}$ & $7.67 \pm 0.2$ \\
\hline & Chloride & $2960 \pm 37$ \\
\hline
\end{tabular}

\subsection{Analytical Methods: $s C O D, B O D_{5}, T O C$}

Soluble COD (sCOD) was measured to avoid the interference of fungal suspended biomass and particulate following the laboratory methods according to the Standard Methods for examination of 
Water and Wastewater [37] and was prepared by filtering $2.5 \mathrm{~mL}$ of leachate through Grade 1 Whatman filter paper, diluted 1:10 with deionized water, to reduce the color interference, and analyzed by the use of Hach digestion vials (high rate vials 20-1500 COD mg L ${ }^{-1}$ ) [37], using dichromate method and Hach spectrophotometer (Spectrophotometer, Loveland, CO, USA) procedure DR2800. Removal efficiency for sCOD was calculated as the percentage depleted at each time of incubation with reference to time 0 . The $\mathrm{BOD}_{5}$ was measured according to the standard methods as reported in [37]. Total Organic Carbon (TOC) was measured with the Hack LCK380 kit (Hach Lange, Milano, Italy), following [37] and according to the manufacture's protocol. A total of six replicates were analyzed for sCOD, $\mathrm{BOD}_{5}$, TOC measurements.

\subsection{Respirometric Test}

The conventional procedure for COD fractioning through respirometric tests was adopted, as described in [38]. The Oxygen Uptake Rate (OUR) due to the dosing of the samples, was used to estimate the soluble biodegradable COD (sbCOD) fractions. The oxygen consumption related to endogenous decay of biomass was subtracted from the whole oxygen consumption. The activated sludge used was obtained from Cuoio Depur WWTP. Respirometric tests were performed at pH 7.8 dosing $100 \mathrm{~mL}$ leachate previously filtered with $0.45 \mu \mathrm{m}$ filters (526.0 mg/L COD). In order to exclude the consumption of oxygen related to the nitrification, the respirometric tests were carried out in two identical vessels with 1.2 L of activated sludge with a concentration of $3 \mathrm{~g} / \mathrm{L}$ of Volatile Suspended Solids (VSS). In one of these vessels, nitrifying bacteria where inhibited by the addition of $40 \mathrm{~mL}$ of a $1 \mathrm{~g} / \mathrm{L}$ of allylthiourea (ATU) solution, to exclude the consumption of oxygen related to the nitrification. The respirometric tests were performed with a respirometer (MARTINA, Spes S.r.l., Caprarola, Viterbo, Italy). The MARTINA respirometer/titrimeter can operate as an open static liquid-flowing gas/static gas (LFS/LFF) respirometer. The control unit was able to perform two tests in two (2 L) plexiglass vessels simultaneously. The two jacketed vessels were each connected to a thermostatic bath (SBF 7, Falc, (Falc Instruments, Bergamo, Italy), continuously mixed with magnetic agitators, and monitored with a temperature probe, a Hamilton $\mathrm{pH}$ probe and a Dissolved Oxygen (DO) probe (CellOx 325, WTW, Germany). The control unit was able to stabilize the $\mathrm{pH}$ set point by dosing with $\mathrm{HCl}$ and $\mathrm{NaOH}$ solutions $(0.1 \mathrm{M})$ through a total isolation micro solenoid valve (D301V51, Sirai srl, Marghera, Italy). The control unit allows the switching on and off of the aeration in order to calculate OUR and maintain the DO in the reactor within two selected DO thresholds. A total of six replicates were analyzed for respirometric tests.

\subsection{Enzymatic Activities}

Manganese dependent and Manganese independent Peroxidases activity were determined spectrophotometrically following the protocol of [39]. Laccase (Lac) activity was measured by the oxidation of 2,2' -azino-di (3-ethylbenzothiazoline-6- sulfonic acid) (ABTS) [40] in a reaction buffer containing $0.4 \mathrm{mM}$ ABTS in $100 \mathrm{mM}$ sodium acetate, $\mathrm{pH} \mathrm{5,} \mathrm{at} 37^{\circ} \mathrm{C}$. Analytical triplicates were performed for each sample. A mixture of leachate and buffer without substrate was prepared as a blank for each sample. All measurements were performed in quadruplicate, in microtiter plates. Increase in absorption was measured using a microplate reader (Spectra, SLT GmbH, Grodig, Austria) at $1 \mathrm{~min}$ intervals for $6 \mathrm{~min}$. The enzymatic activity recorded the absorbance variation at $420 \mathrm{~nm}$ caused by the formation of a radical cathione deriving from the oxidation of ABTS. The data were recorded by the Easy Fit program, on Spectra microplate reader (Spectra, SLT GmbH, Grodig, Austria). One unit of laccase activity $(\mathrm{U})$ was defined as catalyzing the transformation of one micromole of ABTS per $\mathrm{mL}$ per min. The coefficient of molar extinction is $36,000 \mathrm{M}^{-1} \mathrm{~cm}^{-1}$.

\subsection{Batch Tests on Different Old Leachates}

The depletion of the sCOD was monitored in $1000 \mathrm{~mL}$ Erlenmeyer flasks containing $250 \mathrm{~mL}$ old LFL and the fungal biomass, closed with a rubber stoppers and maintained on an orbital shaker at 
$150 \mathrm{rpm}$ at $23 \pm 1^{\circ} \mathrm{C}$ in the dark. The fungal biomass was inoculated as: (i) fungal biomass immobilized on PUF in the case of the old Cuoio Depur WWTP LFL; and (ii) suspend fungal biomass from MEB in the case of the Summit Road old LFL. Three independent biological replicates were conducted for each condition. Three not inoculated flasks, incubated under the same conditions, served as the negative control and were analyzed in parallel to inoculated flasks. At each time point of analysis, the supernatants of three Erlenmeyer flasks were harvested, the fungal biomass was separated, and the clarified supernatant and cell mass were analyzed separately. Enzymatic activities in the clarified supernatants were measured.

\subsection{Reactor Experiments: Structure and Operating Conditions}

Two bench-scale reactors equipped with an inlet aerator system and one air filter on the outlet were used in these experiments. A schematic representation of the reactor is showed in the graphical abstract. The total reactor volume was $2.0 \mathrm{~L}$ and the working volume was $1.5 \mathrm{~L}$. The Hydraulic Retention Time (HRT) was three days. The reactors were connected to two tanks and one peristaltic pump (TEC-R, Aqua Industrial Group, Regio Emilia, Italy) for the inlet. The inlet/outlet flow was of $500 \mathrm{~mL} /$ day LFL, with six reactor cycles consisting of $1 \mathrm{~h}$ of work and $3 \mathrm{~h}$ of stop, feeding $83.3 \mathrm{~mL} / \mathrm{h}$ LFL. The same volume of fed leachate was automatically discharged. Any additional carbon source was added during the treatment. Two reactors were designed to test the effects of mycoaugmentation and the autochthonous LFL, respectively, on the removal of contamination and toxicity. The reactor, R1D1, was inoculated with the Lambertella sp. The reactor, R2D2, containing the same number of not inoculated PUF, was used as control (in presence of PUF not without fungal inoculum). The fungal biomass immobilized on PUFs has been inserted into a net with a mesh that allows both the oxygen and leachate recirculation. The control reactor was filled with empty PUFs. The net was fixed in the inner side of the robber stopper, used to close the reactor system ("hanging biomass"). The parameters measured during the process were TOC and enzymatic activity. A total of six replicates were analyzed for TOC and enzymatic activity.

\subsection{Ecotoxicological Assay: Vicia Faba System Model}

Cytotoxicity and mutagenicity effects of the tested LFLs, before and after the fungal treatments, were observed on seeds of $V$. faba L. according to [41]. Three Petri capsules with 10 seeds per capsule were prepared. These were stored overnight under running tap water, at $24^{\circ} \mathrm{C}$. The following day, the seeds were rinsed, and the water was drained. Petri capsule were prepared for seed incubation as follows: the lid of the capsule was internally covered with a paper disc wetted with $1 \mathrm{~mL}$ of deionized water, for avoiding dehydration of seeds, which were layered on a paper disc on the bottom of the Petri capsule. The paper disc on the bottom of the Petri capsule was wetted with $5 \mathrm{~mL}$ of LFL from the different treatment times. The control capsules were prepared adding deionized water to both paper discs. The capsules containing seeds were incubated at $24{ }^{\circ} \mathrm{C}$ for $72 \mathrm{~h}$ in the dark. Root lengths were measured after $72 \mathrm{~h}$ of incubation. With a scalpel, approximately $0.5-1.5 \mathrm{~cm}$ of each primary root was cut and collected into a single vial. Root tips were fixed in Carnoy fixative solution (EtOH and Acetic Acid 3:1) for $24 \mathrm{~h}$, successively replaced with 70\% EtOH. The root tips were colored using the Feulgen technique, specific for the DNA [42]. For each root tip, 1.000 cells were analyzed by counting different fields of the slide. Parameters such as root elongation, mitotic index, and micronuclei index were evaluated.

\subsection{Statistical Analysis}

All the statistical analyses were performed in GraphPad Prism (Version 8.2.1) (GraphPad Software, San Diego, CA, USA). All the data were analyzed with the aid of two-way ANOVA, using Sidák as a post hoc test. The means were separated using the Bonferroni correction test $(p \leq 0.05)$. 


\section{Results}

\subsection{Batch Tests on Old Leachate with Fungal Suspended Biomass}

Lambertella sp. was tested for the capability to deplete the sCOD of the Summit Road old LFL, whose characteristics are reported in Table 1.

The $\mathrm{BOD}_{5}$ of the leachate was lower than $0.27 \mathrm{mg} \mathrm{O}_{2} / \mathrm{L}$, indicating that the leachate can be classified as an old leachate, characterized by the high recalcitrance to biodegradation of the residual COD [7]. The fungal strain Lambertella sp. was inoculated in the old leachate as suspend biomass in the presence of $0.1 \%(v / v)$ of MEB to provide a readily available source of carbon and energy to the fungal strain, in order to facilitate its adaptation to the growth conditions. To evaluate the fungal potential for LFL treatment, the measurement of the sCOD was selected instead of the measurement of the COD, to avoid the interference that suspended fungal biomass might cause during the measurements.

The depletion of the sCOD (Figure 1) was observed only in presence of the fungal inoculum starting from the second day of incubation, reaching $72 \%$ depletion after 13 days. During the incubation laccase, Mn dependent and Mn independent peroxidases activities were measured every two days. No enzymatic activity was recorded considering that limit of detection of laccase of $0.5 \mathrm{U} / \mathrm{L}$, and for both the peroxidases of $0.2 \mathrm{U} / \mathrm{L}$.

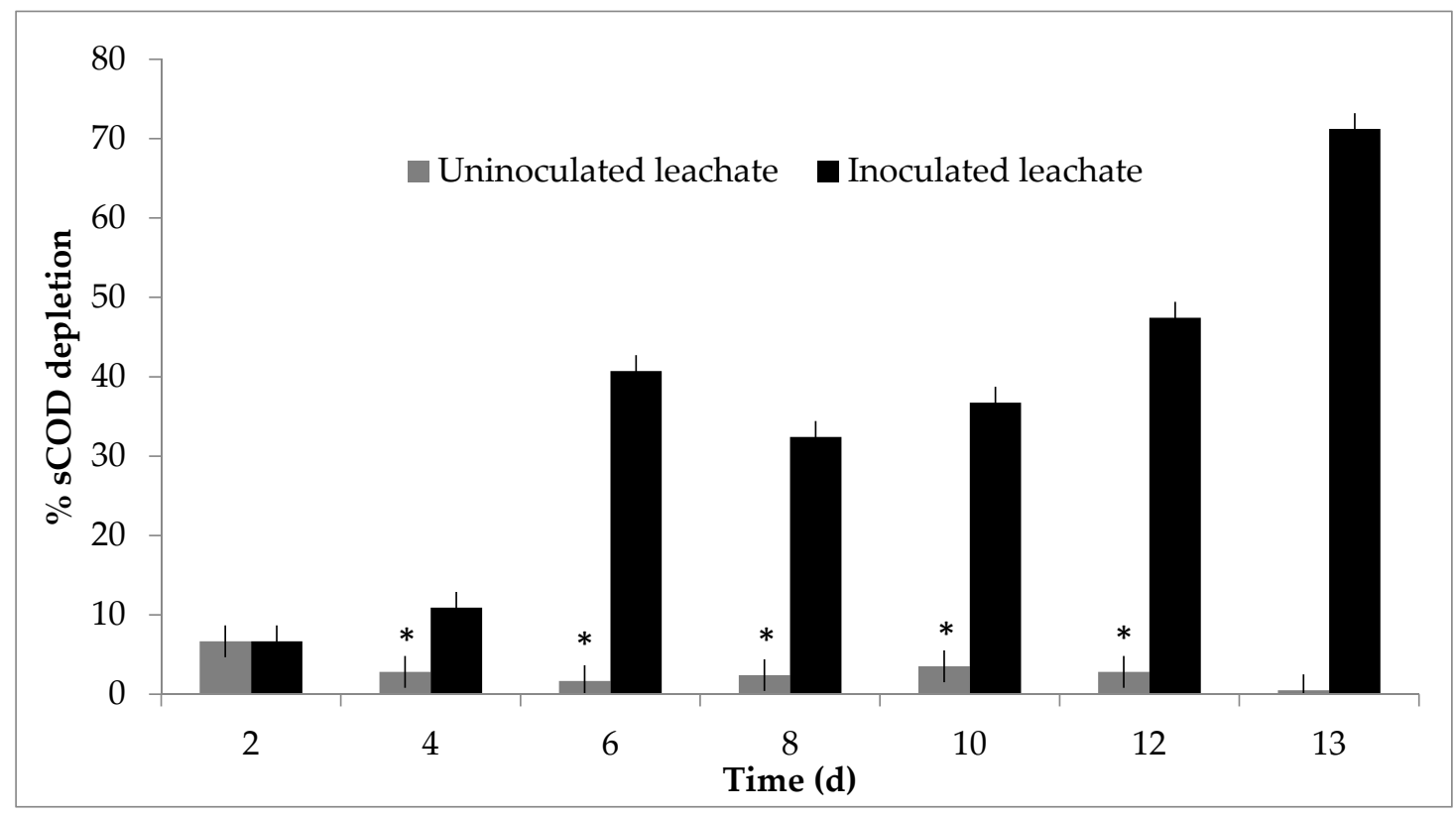

Figure 1. Percentage of sCOD depletion in Summit Road old LFL by using the Lambertella sp. as suspended biomass in presence of $0.1 \%(v / v)$ Malt Extract Broth (MEB). Values represent mean values of the percentage of sCOD depletion from three replicates with reference to the initial concentration. Bars represent the standard deviation (SD) among the three replicates of analysis. All the values are significantly different from the corresponding value at the previous time of analysis at the $1 \%$ level $(p<0.01)$ with the exception of the bars with asterisk $\left(^{*}\right)$.

\subsection{Batch Tests on Old Leachate with Immobilized Fungal Biomass}

The growth of a metabolizing biomass on a support is of potential advantage for application, since biofilm are in general more resistant to variation of operational conditions (temperature, $\mathrm{pH}$, inhibiting compounds). Moreover, depending on the technology applied for biomass detachment and separation, it would be easy to recover and reuse the excess biomass for other application, such as for bioaugmentation in other reactors. Thus, the Lambertella sp. biomass immobilized within PUFs, and in the presence of $0.1 \%(v / v)$ MEB, was used to treat old LFL from the Cuoio Depur WWTP (Table 1). 
In this case the leachate was characterized by a measurable $\mathrm{BOD}_{5}$, suggesting a higher biodegradability with reference to Summit Road old LFL; however, the ratio between the ratio between the $\mathrm{BOD}_{5} / \mathrm{COD}$ is still referable to an old leachate [7]. The $45 \%$ depletion of sCOD was observed after 35 days of treatment (Figure 2). On the other hand, no sCOD depletion was observed in the control flasks up to 28 days of incubation, even though the $20 \%$ of sCOD depletion was recorded in the control flasks after 35 days of incubation. During the incubation Mn dependent, independent peroxidases and laccase activities were measured every two days. No enzymatic activity was recorded.

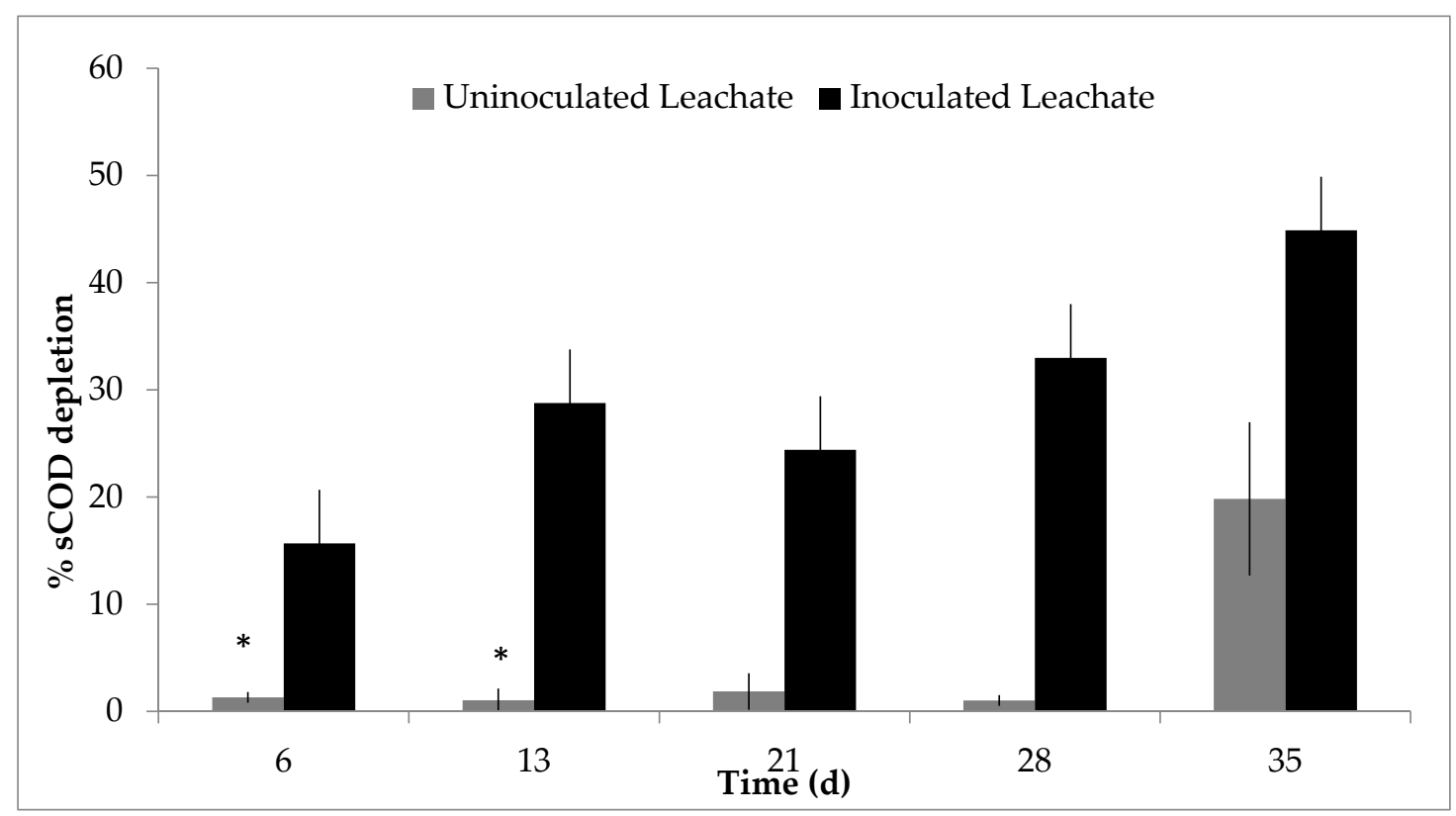

Figure 2. Percentage of sCOD depletion in Cuoio Depur old LFL using Lambertella sp. immobilized on PUFs, in presence of $0.1 \%(v / v)$ of Malt Extract Broth (MEB). Values represent mean values of the percentage of SCOD depletion from three biological replicates with reference to the initial concentration. Bars represent the standard deviation (SD) among the three replicates of analysis. All the values are significantly different from the corresponding value at the previous time of analysis at the $1 \%$ level $(p<0.01)$, with the exception of the bars with asterisk $\left(^{*}\right)$.

\subsection{Reactor-Scale Experimental Setup: Tests on Intermediate Leachate with Immobilized Fungal Biomass}

The immobilized fungal biomass, in the absence of a co-substrate, was used to treat an intermediate LFL from Cuoio Depur WWTP, in a lab scale reactor, operated in a continuous mode for three months. The absence of co-substrate was tested because of the need to design a low cost, sustainable process that did not require the addition of different carbon sources. Two bioreactors were operated in continuous mode for 90 days, as close systems. One of the bioreactors was inoculated with the fungal biomass immobilized on PUFs, while the other was a reactor not inoculated and utilized as a control reactor. The leachate was characterized by a residual $\mathrm{BOD}_{5}$ and a very low COD (Table 1 ). The ratio between the two was relative to the classification of an intermediate leachate [7]. To evaluate the efficacy of the myco-based treatment, the reduction of TOC, rather than SCOD, was quantified, because of the high concentrations of chloride in the intermediate LFL in study. High concentrations of chlorides eventually interfere with sCOD quantification $[43,44]$.

During the start-up phase of the process (0-15 day), an initial TOC depletion was observed only in the inoculated reactor, even though, in the same reactor, a TOC increase was observed between day 4 and day 15 (Figure 3). 


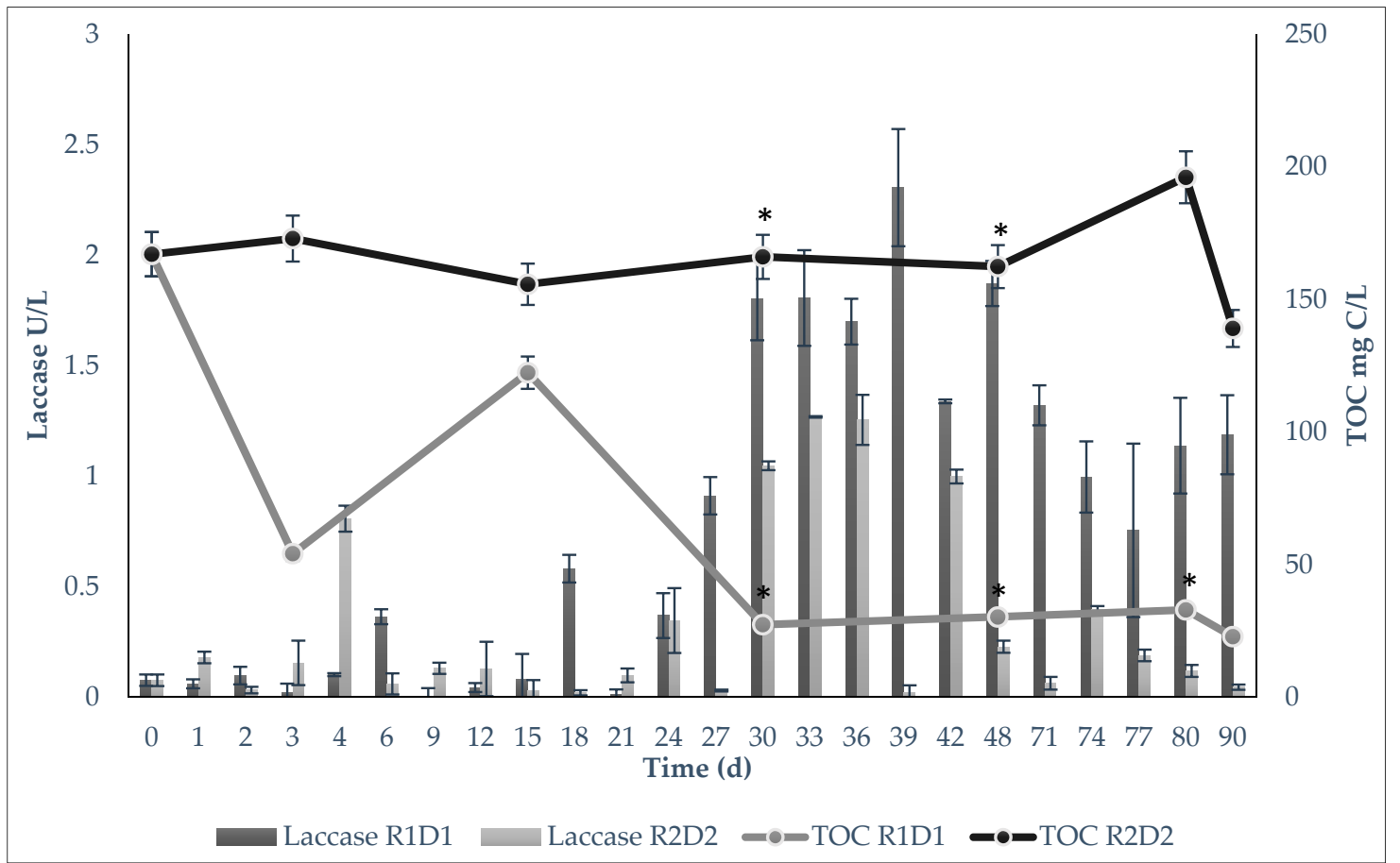

Figure 3. Laccase activity and TOC trend in Cuoio Depur intermediate LFL treating bioreactors using Lambertella sp. immobilized on PUFs. R1D1 myco-augmented bioreactor, R2D2 not inoculated bioreactor (Control). Values represent mean values of the level of laccase and TOC from three biological replicates for time of analysis. Bars represent the standard deviation (SD) among the three replicates of analysis. All the values are significantly different from the corresponding value at the previous time of analysis at a $1 \%$ level $(p<0.01)$, with the exception of the values with asterisk $\left.{ }^{*}\right)$, which are statistically not different.

In the inoculated reactor, between day 4 and day 15, the production of fungal spores was visually observed (data not shown). The production of spores was reasonably associated with the stress conditions of growth that the fungal strain encountered in the reactor. Growth under stress condition might be associated with cellular lysis and production of cellular debris, and/or release of secondary metabolites. These events might be associated with the increase of the TOC values recorded in the inoculated reactor. At the same time, the disappearance of spores after 15 days of incubation in the inoculated reactor and the progressive depletion of the TOC up to $90.2 \%$, after 90 days of incubation, might be interpreted as an indication of the fungal overcoming the stressful growth conditions and adaptation to the reactor operating conditions, determining a nearly total depletion of the residual TOC. During the same time interval of analysis and for all the time interval analyzed, the control reactor showed a constantly higher TOC with reference to the inoculated reactor with a reduction of the $13 \%$ after 90 days of incubation.

Mn dependent, independent peroxidase, and laccase activities were measured at every sampling time. No peroxidase activity was recorded. Laccase activity was recorded in both reactors over the 90 days of incubation (Figure 3). Laccase activity was always lower in the control reactor (R2D2) compared with the inoculated reactor (R1D1), and in the inoculated reactor, an increase in laccase activity was observed in correspondence with the drop of the TOC, after 30 days of incubation.

At the end of the 90 days of incubation, the residual Soluble Biodegradable COD (sbCOD) fractions of the inoculated and not inoculated LFLs at the end of the myco-based treatment was quantified by respirometric tests and compared to the value measured for the untreated LFL. Respirometric tests results indicated that the percentage of sbCOD depleted was similar for the untreated leachate and for the outlet of the control reactor after 90 days of incubation: $36 \pm 1.5 \%$ and $38 \pm 1.5 \%$, respectively. On the other hand, the same portion was significantly lower for the outlet of the inoculated reactor, $7 \pm 1.5 \%$, 
indicating that the fungal inoculum was capable of depleting a higher portion of the intermediated LFL's recalcitrant to biodegradation load.

\subsection{Ecotoxicological Assay}

The phytotoxicity, cytotoxicity, and mutagenicity of the old and intermediate leachates from Cuoio Depur WWTP was quantified using the $V$. faba model [41] (Figures 4 and 5).

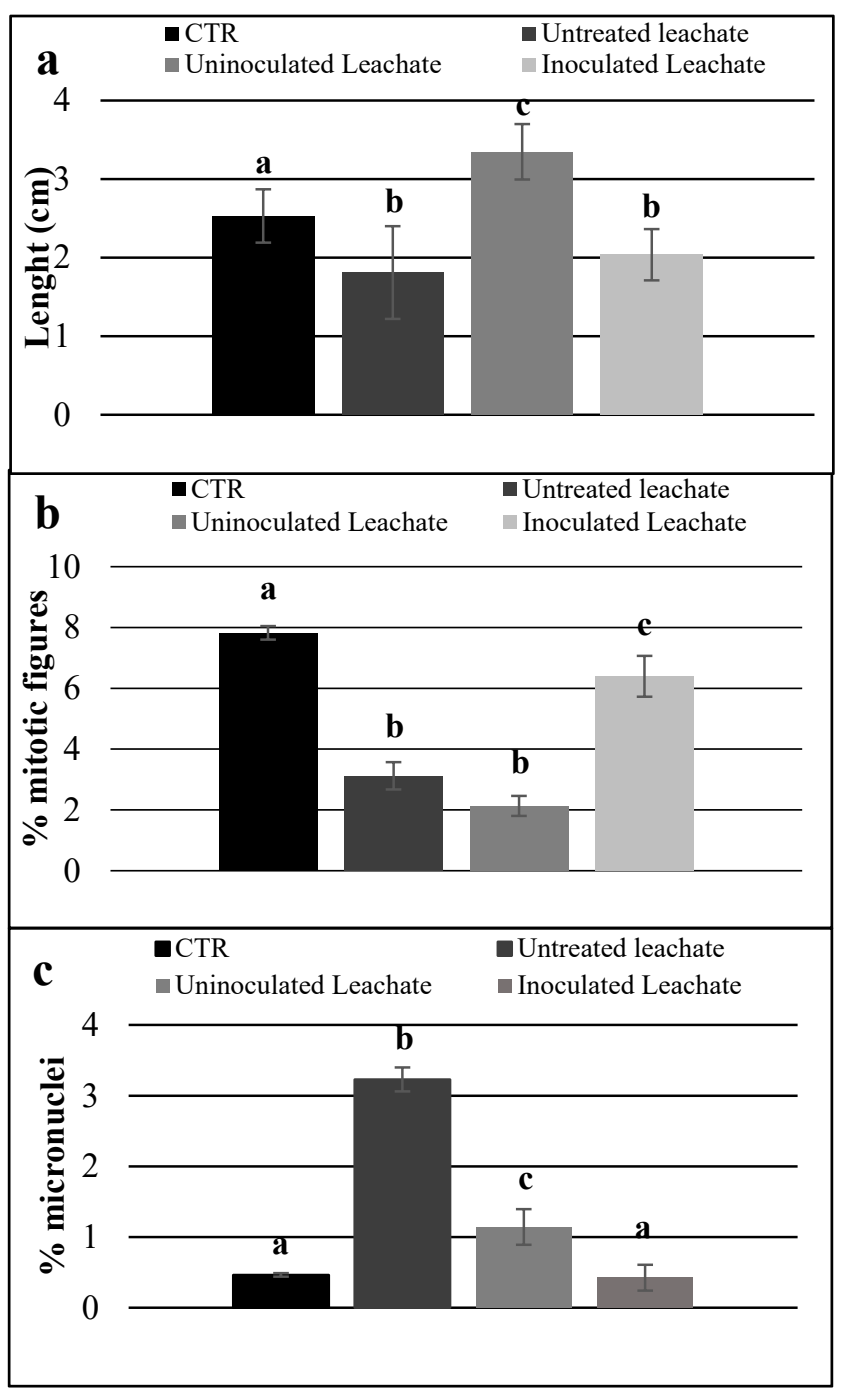

Figure 4. Panel (a) Phytotoxicity; (b) Cytotoxicity; (c) Genotoxicity of the old Cuio Depur WWTP leachate before and after the myco-based treatment. All the values are statistically different from the corresponding value at the untreated leachate (CTR) at the $1 \%(p<0.01)$. Bars represent the standard deviation (SD) among the three replicates of analysis. Statistically significant differences of the data compared to the control (deionized water) are indicated by letters on the top of the bars. 

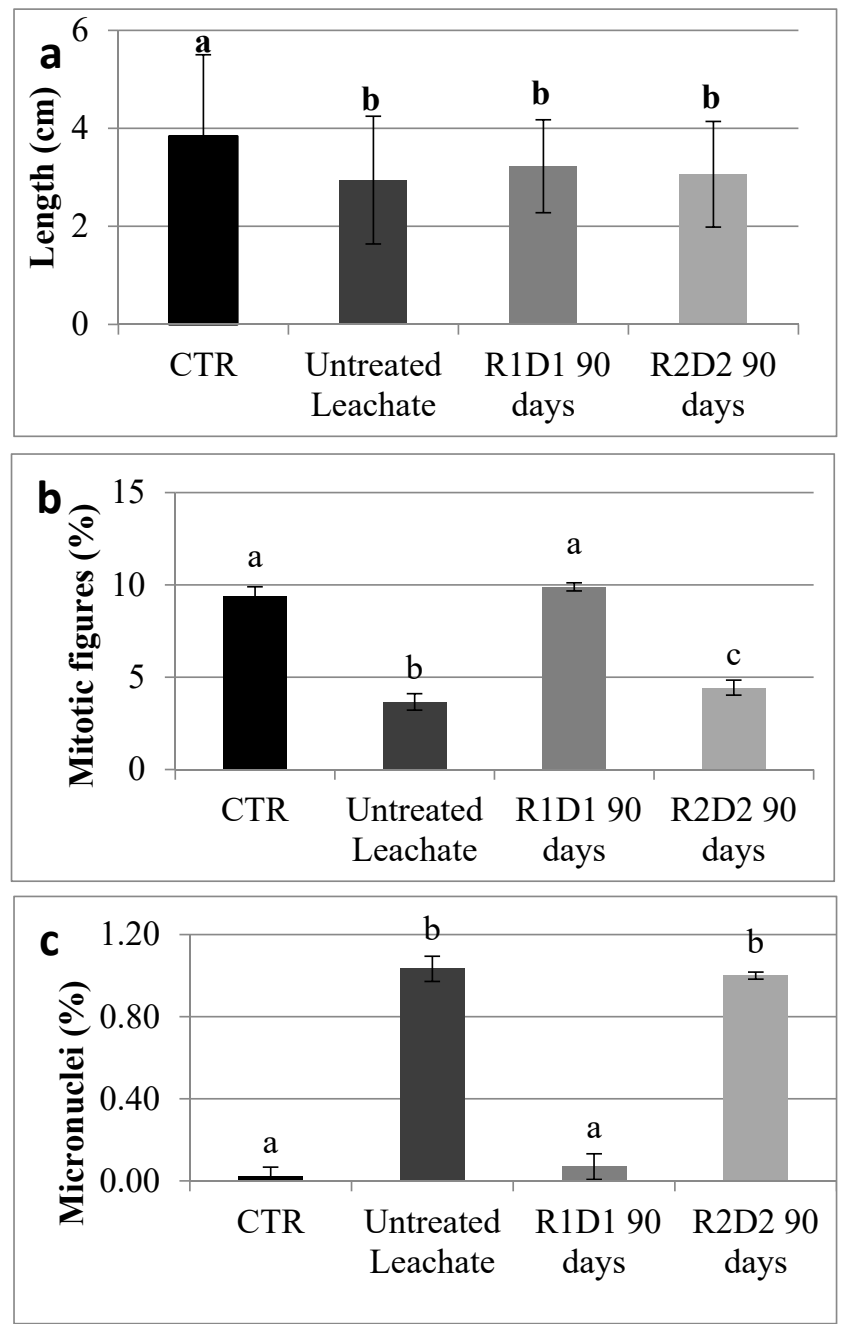

Figure 5. Panel (a) Phytotoxicity; (b) Cytotoxicity; (c) Genotoxicity of the intermediate Cuoio Depur WWTP intermediate leachate before and after the myco-based treatment. All the values are statistically different from the corresponding value at the untreated leachate (CTR) at the $1 \%(p<0.01)$. Bars represent the standard deviation (SD) among the three replicates of analysis. Statistically significant differences of the data compared to the control (deionized water) are indicated by letters on the top of the bars.

In relation to the old leachate, the untreated leachate and the leachate not inoculated with the fungal strain but still incubated in co-metabolic batch conditions, showed phytotoxic effects. For the untreated leachate, the phytotoxicity was associated with a hormetic effect (Figure 4a). In fact, the increase in root lengthening with reference to the control condition, consisting in incubation of seeds in sterile water, is defined as the hormetic effect, and it is preferable to phytotoxicity [45]. On the other hand, both the not inoculated and the inoculated leachate determined a significant reduction of the length of the roots of $V$. faba with reference to the control (Figure 4a).

A cytotoxic effect was also observed for all the leachates, even though the myco-based treatment corresponded to a lighter effect (Figure $4 \mathrm{~b}$ ). Results obtained suggested that the phytotoxicity of the leachates on the root tip of $V$. faba was actually determined by a combination of effects, inhibiting the mitotic activity or the proliferative capacity of the cells of the apical meristem and the lengthening of the cells of the root tips.

On the other hand, mutagenicity was also very high for the different leachates. A significant increase in the number of micronuclei was recorded. An exception occurred with the inoculated old 
leachate that, at the end of the treatment, showed a number of recorded micronuclei in the root tips, comparable to the one recorded in the control (Figure 4c).

In relation to the intermediate leachate, the untreated LFL was also characterized by a significant level of phytotoxicity that, also in this case, was not removed by the myco-based treatment, both in the inoculated and in the control reactors (Figure 5a). However, in the case of the intermediate leachate, the cytotoxicity and mutagenicity, both very high for the untreated leachate and for the not inoculated leachate incubated in the control reactor, reached the same level as the control (Figure 5b,c).

\section{Discussion}

We have foreseen the use of an Ascomycete, since Ascomycota are dominant in wastewater streams [30,35], in different environmental matrices [31] and more in general in contaminated matrices [46]. They are capable of transforming environmental pollutants, overcoming some of the limitations observed for Basidiomycetes with respect to growth in neutral $\mathrm{pH}$, resistance to adverse conditions and capability to chelate metal ions, leading not only to the decontamination of the treated matrices but also to their detoxification [47]. Moreover, Ascomycete fungi produce non ligninolytic peroxidases, neutral laccases, and tyrosinases, capable of a partial lignin-oxidation and extracellular polymerisation of polyphenols [48], eventually involved in the transformation of several recalcitrant compounds. However, as far as we know, the exploitation of Ascomycetes in the treatment of LFLs has been restricted to Saccharomyces cerevisiae [16]. Thus, Ascomycetes' metabolic capacities, might have been underestimated in the design of myco-based approaches to the decontamination of LFLs. In fact, the Lambertella sp. strain, here exploited and previously characterized for its capacity to transform environmental contaminants recalcitrant to biodegradation [37], resulted to be mandatory for depletion of the recalcitrant portion of old and intermediate leachates. On the other hand, the fungal activity might have triggered a transformation process promoting the further transformation activity of the autochthonous microbial community. In fact, the present experimentation was performed on real, not sterile leachates, in presence of autochthonous microbial communities. These latter resulted to be not competent to deplete the chemically stabilized organic and inorganic fraction of the leachates, even if incubated under co-metabolic conditions. A partial metabolic activity of these communities was recovered only in presence of a residual BOD $_{5}$ in the old Cuio Depur WWTP leachate. However, their participation to the process of depletion of the recalcitrant fraction in LFL, in synergism with the fungal metabolism, cannot be excluded.

In general, it is reasonable to assume that autochthonous microorganisms would be able to biodegrade the organic fraction of the matrices of origin, more efficiently than allochthones [49]. However, most of the time, this was not observed with the aging of LFLs. In this context, it is reasonable to assume that allochthonous microbial communities of even consolidated and operating bio-based plants (e.g., LFL receiving activated sludge or anaerobic digesters) might also be hindered in their metabolic activity by the chemically stabilized organic matter characterizing old LFLs. However, the Lambertella sp. resulted to be very effective in triggering the transformation and/or directly metabolizing recalcitrant compounds in old LFLs. In fact, the fungal strain was not only able to compete with the autochthonous microbial community already present in the LFL, but activated a more efficient biodegradative metabolism.

Our data are consistent with the results reported by [26] in which the more extensively described exploitation of a Basydiomicetes, the Dichomitus squalenes, was used to treat an old LFL. The exploitation of Basidiomycetes in the transformation of recalcitrant organic fractions because of their battery of ligninolitic extracellular enzymes has been extensively reported and the extracellular enzymatic activity has been extensively used to assess the metabolic capacity of fungal candidates in the depletion of contaminants $[34,36,48]$. However, during the here reported in batch experimentation, neither Mn dependent and independent peroxidase, nor laccase activities were recorded during the experimentation. Some authors $[50,51]$ reported the presence of quencher of UV-light emissions in LFLs, with the consequent hindering of the recording of enzymatic activities [51]. On the other hand, 
even though the quenching activity of the chemical composition of the LFL cannot be excluded, the involvement of the intracellular metabolism of fungi, based on cytochromes activities in the depletion of the LFL's sCOD, might also be possible.

At the same time, laccase activity was actually recorded in the reactors working in continuous mode, treating the intermediate leachate. The enzymatic activity was recorded also in absence of the fungal inoculum, even though at lower levels with reference to the reactor inoculated with the Lambertella sp. In this context, it is interesting to note that the production of laccase was associated with the depletion of the recalcitrant organic portion of the leachate, only in presence of the fungal inoculum, which suggests catalytic differences between the enzymatic activity recorded in the inoculated reactor and in the not inoculated one. In this latter case, the laccase activity is reasonably associated with the LFL autochthonous microbial community, actually resulting not capable of depleting the corresponding recalcitrant fraction, suggesting that the autochthonous bacterial laccases might be characterized by redox potentials too low to catalyze a transformation of the chemical structures of the stabilized fraction of an old LFL. On the other hand, the fungal candidate demonstrated the capability to compete and or to have a synergistic activity with the microbial community autochthonous to the leachate and to catalyze a fast abatement of its organic fraction. The Lambertella sp. here exploited has already been reported as capable of producing laccases, whose production has been associated with its capacity to oxidize heavy hydrocarbons [37]. Additionally, the involvement of the enzymatic activity in the depletion of the recalcitrant organic fraction of the intermediate leachate cannot be excluded.

Respirometric tests confirmed that Lambertella sp. was actually capable of removing the highest fraction of refractory organic and inorganic fraction characterizing the intermediate LFL, envisaging good potentiality for its exploitation in the improvement of the actual approach to the treatment of noxious, mature leachates. As an example, chemical-physical treatments such as reverse osmosis has been one of the most widely used methods for treating LFLs in recent years [8]. The disadvantage of treating leachate with reverse osmosis is the managing of bottlenecks related to membrane fouling, which decreases the treatment effectiveness. Consequently, attention has shifted to the use of combined biological and chemical-physical treatments. In particular, biological treatments as pre-treatments of leachates have been used to reduce the organic load of the LFLs that either contributes directly to organic fouling, or provides carbon sources for the development of biofilms on the reverse osmosis membrane surfaces [52]. Thus, integration of biological treatments and reverse osmosis processes are actually considered promising in LFL treatments; however, they are mostly exploited in the treatment of young LFLs. Results here obtained suggest the compatibility of the combination of an upstream bio-based treatment to downstream chemical-physical treatments not only for young leachates but also for more recalcitrant mature leachates.

Moreover, it should be mentioned that negative effects of even low concentrations of the different classes of pollutants characterizing the LFLs are well documented [52,53]. In the present experimentation, results obtained indicate that the depletion of the recalcitrant organic fraction of leachates was associated mainly to the depletion of their mutagenicity more than their phyto- and cytotoxic effects. The reasons for this are unclear. The biodegradative activity of the Lambertella sp. was actually evidently associated with an organic fraction particularly recalcitrant to biodegradation. It is known that organic moieties characterized by aromatic structures are very recalcitrant to biodegradation and might be associated with a genotoxic affect. On the other hand, both the residual organic fraction and the inorganic contaminants in LFLs might also be associated with a phytotoxic effect. However, their depletion is evidently not significant in the myco-based processes determining a possible persistence of the phyto- and cytotoxicity of the leachates. In relation to the intermediate leachate, the myco-based treatment was associated also to the reduction of the cytotoxic effect.

Results obtained are very encouraging in the case of adoption of the myco-based approach for the treatment of mature leachates, since the mutagenicity test used in this work, based on evaluating the formation of micronuclei, which is a direct indication of the ability of a genotoxic agent to disrupt or break chromosomes, is actually an indicator of clastogenicity of the matrices. Eventual clastogenic 
effects of LFLs are much more noxious and dangerous for the environment compared to phytotoxic effects, because plants can overcome the latter via a plethora of adaptive mechanisms. In contrast, the formation of micronuclei causes the loss of genetic information because of non-disjunction events during mitosis. Our data demonstrate that the myco-based process was capable of significantly reducing the clastogenic effects of the LFLs. Chemical, ecotoxicological, and microbiological characteristics of LFLs should be evaluated to assess the environmental risks posed by landfill emissions, because of the evidence that landfill leachates contain an unknown number of xenobiotic organic compounds, which constitute a potential risk to the quality of surface/ground waters, when released into the environment $[30,54,55]$. There is still a limited database, and an urgent need, for more information about these contaminants with respect to both their identity and concentrations, as well as to their toxicity. However, their variability in both nature and concentrations makes the goal extremely challenging, frustrating the possibility of designing processes dedicated to the single toxic agent. Thus, the design of sustainable treatments capable of reducing the toxicity of different kind of toxic intermediates and the toxicity related to their co-presence along with their concentrations is desirable. In this context, the exploitation of the Lambertella sp. seems to be promising.

\section{Conclusions}

The purpose of the present work was to develop a bio-based process exploitable as a pre-treatment stage in consolidated LFL treatment chains. More precisely, the goal was consistent with the design of a bio-based treatment to eventually support both chemical-physical and biological already consolidates trains of treatments, because of the possibility to decrease the high organic load, recalcitrant to biodegradation, which contributes to the loss of efficiency of every train of wastewater treatment, when facing LFLs. The results obtained indicate that the myco-based approach was capable to decrease the recalcitrant portion of the organic load in diverse leachates, eventually deriving from different climatic zones, but all defined as mature (old and intermediate). The results suggest the possibility of the combination of the described approach to already consolidated treatments, for implementing the final quality of the resulting treated leachate. In this context, the myco-based process resulted to be very promising also in relation to the capability of Lambertella sp., to reduce the clastogenic effects of the organic fraction of the treated LFLs, indicating that Lambertella sp. may be a very promising candidate for the treatment of mature leachates. The different nature of the leachates in the study suggests a Lambertella sp. non-specific mechanisms of depletion, which might be related to the production of extracellular laccases. However, the involvement of the microbial communities autochthonous to the leachates on the myco-based transformed organic fraction cannot be excluded.

Author Contributions: G.S.: Conceptualization, Investigation, Validation, Data curation, Writing-Original Draft; Q.Y.: Project administration, Data curation, Formal analysis; I.C.: Data curation, Formal analysis; A.B.: Data curation, Formal analysis; F.S.: Methodology, Software; S.B.: Data curation; D.B.L.: Writing-Reviewing and Editing, Data curation, Formal analysis; G.M.: Conceptualization, Validation, Data curation, Project administration; G.P.: Project administration; S.D.G.: Conceptualization, Validation, Data curation, Writing-Reviewing and Editing, Supervision, Project administration. All authors have read and agreed to the published version of the manuscript.

Funding: This research was funded by the MANUNET III FUNCELL Project (grant number MNET17/ENER-1143), and the Bioresnova project (grant number 135/11) co-financed by Fondazione Pisa and the Department of Biology, University of Pisa.

Conflicts of Interest: The authors declare no conflict of interest.

\section{References}

1. Shalini, S.S.; Joseph, K. Nitrogen management in landfill leachate: Application of Sharon, Anammox and combined Sharon-Anammox process. Waste Manag. 2012, 32, 2385-2400. [CrossRef] [PubMed]

2. Tigini, V.; Spina, F.; Romagnolo, A.; Prigione, V.; Varese, G.C. Effective biological treatment of landfill leachates by means of selected white rot fungi. Chem. Eng. Trans. 2013, 32, 265-270. 
3. Wang, K.; Li, L.; Tan, F.; Wu, D. Treatment of landfill leachate using activated sludge technology: A review. Archea 2018, 10-20. [CrossRef] [PubMed]

4. Brito, G.C.B.; Lange, L.C.; Santos, V.L.; Amaral, S.; Moravia, W.G. Long-term evaluation of membrane bioreactor inoculated with commercial bakers' yeast treating landfill leachate: Pollutant removal, microorganism dynamic and membrane fouling. Water Sci. Technol. 2019, 79, 398-410. [CrossRef] [PubMed]

5. Ghosh, P.; Thakur, I.S. Biosorption of landfill leachate by Phanerochaete sp. ISTL01: Isotherms, kinetics and toxicological assessment. Environ. Technol. 2017, 38, 1800-1811. [CrossRef] [PubMed]

6. Peyravi, M.; Jahanshahi, M.; Alimoradi, M.; Ganjian, E. Old landfill leachate treatment through multistage process: Membrane adsorption bioreactor and nanofiltration. Bioproc. Biosyst. Eng. 2016, 39, 1803-1816. [CrossRef]

7. Luo, H.; Zeng, Y.; Cheng, Y.; He, D.; Pan, X. Recent advances in municipal landfill leachate: A review focusing on its characteristics, treatment, and toxicity assessment. Sci. Total. Environ. 2020, 703, 135468. [CrossRef] [PubMed]

8. Talalai, I.A.; Biedka, P.; Bartkowska, I. Treatment of landfill leachate with biological pretreatment and reverse osmosis. Environ. Chem. Lett. 2019, 17, 1177-1193. [CrossRef]

9. Miao, L.; Yang, G.; Tao, T.; Peng, Y. Recent advances in nitrogen removal from landfill leachate using biological treatments-A review. J. Environ. Manag. 2019, 235, 178-185. [CrossRef]

10. Michalska, J.; Pinski, A.; Zur, J.; Mrozik, A. Selecting Bacteria Candidates for the Bioaugmentation of Activated Sludge to Improve the Aerobic Treatment of Landfill Leachate. Water 2020, 12, 140. [CrossRef]

11. Xu, Q.; Siracusa, G.; Di Gregorio, S.; Yuan, Q. COD removal from biologically stabilized landfill leachate using Advanced Oxidation Processes (AOPs). Process. Saf. Environ. 2018, 120, 278-285. [CrossRef]

12. Chen, W.; Gu, Z.; Wen, P.; Li, Q. Degradation of refractory organic contaminants in membrane concentrates from landfill leachate by a combined coagulation-ozonation process. Chemosphere 2018, 217, 411-422. [CrossRef] [PubMed]

13. da Costa, F.M.; Daflon, S.D.A.; Bila, D.M.; da Fonseca, F.V.; Campos, J.C. Evaluation of the biodegradability and toxicity of landfill leachates after pretreatment using advanced oxidative processes. Waste Manag. 2018, 76, 606-613. [CrossRef] [PubMed]

14. Greń, I.; Zur, J.; Wasilkowski, D.; Mrozik, A. Impact of the biological cotreatment of the Kalina pond leachate on laboratory sequencing batch reactor operation and activated sludge quality. Water 2020, 11, 1539.

15. Mohd Azhar, A.H.; Hamidi, A.A.; Suffian, Y.M.; Rezan, S.A. Optimization and Analysis of Zeolite Augmented Electrocoagulation Process in the Reduction of High-Strength Ammonia in Saline Landfill Leachate. Water 2020, 12, 247.

16. Gasparini Reis, B.; Lemes Silveira, A.; Procópio Tostes Teixeira, L.; Akemi Okuma, A.; Lange, L.C.; Santos Amaral, M.C. Organic compounds removal and toxicity reduction of landfill leachate by commercial bakers' yeast and conventional bacterial based membrane bioreactor integrated with nanofiltration. Waste Manag. 2017, 70, 170-180. [CrossRef]

17. Jakopovic, H.K.; Matošic, M.; Muftic, M.; Curlin, M.; Mijatovic, I. Treatment of landfill leachate by ozonation, ultrafiltration, nanofiltration and membrane bioreactor. Fresenius Environ. Bull. 2008, 17, 687-695.

18. Amaral, M.C.S.; Brito, G.C.B.; Reis, B.G. Comparison of commercial baker's yeast versus bacteria-based membrane bioreactors for landfill leachate treatment. Environ. Technol. 2017, 39, 2365-2372. [CrossRef]

19. Di Gregorio, S.; Giorgetti, L.; Ruffini Castiglione, M.; Mariotti, L.; Lorenzi, R. Phytoremediation for improving the quality of effluents from a conventional tannery wastewater treatment plant. Int. J. Environ. Sci. Technol. 2015, 12, 1387-1400. [CrossRef]

20. Di Gregorio, S.; Gentini, A.; Siracusa, G.; Becarelli, S.; Azaizeh, H.; Lorenzi, R. Phytomediated biostimulation of the autochthonous bacterial community for the acceleration of the depletion of polycyclic aromatic hydrocarbons in contaminated sediments. BioMed. Res. Int. 2014, 2014, 1-11. [CrossRef]

21. Francini, A.; Mariotti, L.; Di Gregorio, S.; Sebastianio, L.; Andreucci, A. Removal of micro-pollutants from urban wastewater by constructed wetlands with Phragmites australis and Salix matsudana. Environ. Sci. Pollut. Res. 2018, 25, 36474-36484. [CrossRef] [PubMed]

22. Moga, I.C.; Bardi, A.; Di Gregorio, S.; Spennati, F.; Munz, G.; Battistini, S.; Iordache, O.G.; Mitran, C.E.; Petrescu, G. Improved biofilm carriers for fungal exploitation in wastewater treatment. IOP Conf. Ser. Mater. Sci. Eng. 2019, 572, 012104. [CrossRef] 
23. Paskuliakova, A.; McGowan, T.; Tonry, S.; Touzet, N. Phycoremediation of landfill leachate with the chlorophyte Chlamydomonas sp. SW15aRL and evaluation of toxicity pre and post treatment. Ecotoxicol. Environ. Saf. 2018, 147, 622-630. [CrossRef] [PubMed]

24. Bardi, A.; Yuan, Q.; Siracusa, G.; Chicca, I.; Islam, M.; Spennati, F.; Tigini, V.; Di Gregorio, S.; Levin, D.B.; Petroni, G.; et al. Effect of cellulose as co-substrate on old landfill leachate treatment using white-rot fungi. Bioresour. Technol. 2017, 241, 1067-1076. [CrossRef] [PubMed]

25. Bardi, A.; Yuan, Q.; Tigini, V.; Spina, F.; Varese, G.C.; Spennati, F.; Becarelli, S.; Di Gregorio, S.; Petroni, G.; Munz, G. Recalcitrant compounds removal in raw leachate and synthetic effluents using the White-Rot fungus Bjerkandera adusta. Water 2017, 9, 824. [CrossRef]

26. Kalcíková, G.; Babic, J.; Pavko, A.; Gotvajn, A.Z. Fungal and enzymatic treatment of mature municipal landfill leachate. Waste Manag. 2014, 34, 798-803. [CrossRef]

27. Spennati, F.; Ricotti, A.; Mori, G.; Siracusa, G.; Becarelli, S.; Di Gregorio, S.; Tigini, V.; Varese, G.C.; Munz, G. The role of cosubstrate and mixing on fungal biofilm efficiency in the removal of tannins. Environ. Technol. 2019, 1-9. [CrossRef]

28. Spennati, F.; Mora, M.; Tigini, V.; La China, S.; Di Gregorio, S.; Gabriel, D.; Munz, G. Removal of Quebracho and Tara tannins in fungal bioreactors: Performance and biofilm stability analysis. J. Environ. Manag. 2019, 231, 137-145. [CrossRef]

29. Tigini, V.; Bevione, F.; Prigione, V.; Poli, A.; Ranieri, L.; Spennati, F.; Munz, G.; Varese, G.C. Tannery mixed liquor from an ecotoxicological and mycological point of view: Risks vs potential biodegradation application. Sci. Total. Environ. 2018, 627, 835-843. [CrossRef]

30. Tigini, V.; Prigione, V.; Varese, G.C. Mycological and ecotoxicological characterisation of landfill leachate before and after traditional treatments. Sci. Total. Environ. 2014, 15, 335-341. [CrossRef]

31. Harms, H.; Schlosser, D.; Wick, L.Y. Untapped potential: Exploiting fungi in bioremediation of hazardous chemicals. Nature. Rev. Microbiol. 2011, 9, 177-192. [CrossRef] [PubMed]

32. Di Gregorio, S.; Becarelli, S.; Siracusa, G.; Ruffini Castiglione, M.; Petroni, G.; Masini, G.; Gentini, A.; Rubia de Lima e Silva, M.; Lorenzi, R. Pleurotus ostreatus spent mushroom substrate for the degradation of Polycyclic Aromatic Hydrocarbons: The case study of a pilot dynamic biopile for the decontamination of a historically contaminated soil. J. Chem. Technol. Biotechnol. 2016, 91, 1654-1664. [CrossRef]

33. Siracusa, G.; Becarelli, S.; Lorenzi, R.; Gentini, A.; Di Gregorio, S. PCB in the environment: Bio-based processes for soil decontamination andmanagement of waste from the industrial production of Pleurotus ostreatus. New Biotechnol. 2017, 39, 232-239. [CrossRef] [PubMed]

34. El-Gohary, F.A.; Kamel, G. Characterization and biological treatment of pre-treated landfill leachate. Ecol. Eng. 2016, 94, 268-274. [CrossRef]

35. Weber, S.D.; Hofmann, A.; Pilhofer, M.; Wanner, G.; Agerer, R.; Ludwig, W.; Schleifer, K.H.; Fried, J. The diversity of fungi in aerobic sewage granules assessed by $18 \mathrm{~S}$ rRNA gene and ITS sequence analyses. FEMS Microbiol. Ecol. 2009, 68, 246-254. [CrossRef] [PubMed]

36. Becarelli, S.; Chicca, I.; Siracusa, G.; La China, S.; Gentini, A.; Lorenzi, R.; Munz, G.; Petroni, G.; Levin, D.B.; Di Gregorio, S. Hydrocarbonoclastic Ascomycetes to enhance co composting of total petroleum hydrocarbon (TPH) contaminated dredged sediments and lignocellulosic matrices. New Biotechnol. 2019, 50, 27-36. [CrossRef]

37. American Public Health Association. Standard Methods for the Examination of Water and Wastewater. In American Water Works Association, Water Environment Federation, 20th ed.; APHA: Washington, DC, USA, 1999.

38. Munz, G.; Gori, R.; Cammilli, L.; Lubello, C. Characterization of tannery wastewater and biomass in a membrane bioreactor using respirometric analysis. Bioresour. Technol. 2008, 99, 8612-8618. [CrossRef]

39. De Jong, E.D.; Cazemier, A.E.; Field, J.A.; de Bont, J.A. Physiological role of chlorinated aryl alcohols biosynthesized de novo by the white rot fungus Bjerkandera sp. strain BOS55. Appl. Environ. Microbiol. 1994, 60, 271-277. [CrossRef]

40. Niku-Paavola, M.L.; Raaska, L.; Itävaara, M. Detection of white-rot fungi by a non-toxic stain. Mycol. Res. 1990, 94, 27-31. [CrossRef]

41. Gustavino, B.; Caciolli, S.; Mancini, L. Guide Line of Micronuclei Test in Vicia Faba for the Evaluation of Mutagenic Effects on Fresh Water and Sediments; ISTISAN Protocol 13/27; Istituto Superiore di Sanità: Roma, Italy, 2013. 
42. Venora, G.; Blangiforti, S.; Ruffini Castiglione, M.; Pignone, D.; Losavio, F.; Cremonini, R. Chromatin organization and computer aided karyotyping of Triticum durum Desf. Cv. Timilia. Caryologia 2002, 55, 91-98. [CrossRef]

43. Baldi, F.; Iannelli, R.; Pecorini, I. Influence of the $\mathrm{pH}$ control strategy and reactor volume on batch fermentative hydrogen production from the organic fraction of municipal solid waste. Waste Manag. Res. 2019, 37, 478-485. [CrossRef] [PubMed]

44. Sivakumar, D.; Rajaganapathy, J.; Anand, R.; Mariavensa, S.; Preethi, S. TOC and COD removal form municipal solid waste leachate using electrocoagulaton method. J. Chem. Pharm. Sci. 2015, 8, 745-751.

45. Ruffini Castiglione, M.; Giorgetti, L.; Becarelli, S.; Siracusa, G.; Lorenzi, R.; Di Gregorio, S. Polycyclic Aromatic Hydrocarbon-contaminated soils: Bioaugmentation of autochthonous bacteria and toxicological assessment of the bioremediation process by means of Vicia faba L. Environ. Sci. Pollut. Res. Int. 2016, 23, 7930-7941. [CrossRef] [PubMed]

46. Godoy, P.; Reina, R.; Calderón, A.; Wittich, R.M.; García-Romera, I.; Aranda, E. Exploring the potential of fungi isolated from PAH-polluted soil as a source of xenobiotics degrading fungi. Environ. Sci. Pollut. Res. 2016, 23, 20985-20996. [CrossRef] [PubMed]

47. Marco-Urrea, E.; García-Romera, I.; Aranda, E. Potential of non-ligninolytic fungi in bioremediation of chlorinated and Polycyclic Aromatic Hydrocarbons. New Biotechnol. 2015, 32, 620-628. [CrossRef] [PubMed]

48. Zavarzina, A.; Lisov, A.; Zavarzin, A.; Leontievsky, A. Fungal oxidoreductases and humification in forest soils. Soil Enzymol. 2011, 22, 207-228.

49. Spina, F.; Tigini, V.; Romagnolo, A.; Varese, G.C. Bioremediation of landfill leachate with fungi: Autochthonous vs. allochthonous strains. Life 2018, 8, 27. [CrossRef]

50. Pastore, C.; Barca, E.; Del Moro, G.; Di Iaconi, C.; Loos, M.; Singer, H.P.; Mascolo, G. Comparison of different types of landfill leachate treatment by employment of nontarget screening to identify residual refractory organics and principal component analysis. Sci. Total. Environ. 2018, 635, 984-994. [CrossRef]

51. Zhao, R.; Novak, J.T.; Goldsmith, C.D. Evaluation of on-site biological treatment for landfill leachates and its impact: A size distribution study. Water Res. 2012, 46, 3837-3848. [CrossRef]

52. Wend, C.F.; Stewart, P.S.; Jones, W.; Camper, A.K. Pretreatment for membrane water treatment systems: A laboratory study. Water Res. 2003, 37, 3367-3378. [CrossRef]

53. Schrab, G.E.; Brown, K.W.; Donnelly, K.C. Acute and genetic toxicity of municipal landfill leachate. Water Air Soil Pollut. 1993, 69, 99-112. [CrossRef]

54. Baderna, F.; Caloni, E.; Benfenati, E. Investigating landfill leachate toxicity in vitro: A review of cell models and endpoints. Environ. Int. 2019, 122, 21-30. [CrossRef] [PubMed]

55. Baderna, D.; Maggioni, S.; Boriani, E.; Gemma, S.; Molteni, M.; Lombardo, A.; Colombo, A.; Bordonali, A.; Rotella, G.; Lodi, M.; et al. A combined approach to investigate the toxicity of an industrial landfill's leachate: Chemical analyses, risk assessment and in vitro assays. Environ. Res. 2011, 122, 603-613. [CrossRef] [PubMed]

(C) 2020 by the authors. Licensee MDPI, Basel, Switzerland. This article is an open access article distributed under the terms and conditions of the Creative Commons Attribution (CC BY) license (http://creativecommons.org/licenses/by/4.0/). 